\title{
Lobbying for size and slice of the quota
}

\author{
Pauli Lappi ${ }^{1}$ (D) \\ Accepted: 16 June 2021 / Published online: 19 July 2021 \\ (c) The Author(s) 2021
}

\begin{abstract}
The formation and allocation of an emission quota are analyzed in a common agency framework with two stages. First, the principals lobby for the size of the aggregate quota. Second, the principals lobby for the individual slices of the quota. It is shown that the slices are allocated such that the marginal profits of the principals are equalized and that the size of the aggregate quota is either set at the efficient level characterized by the Samuelson's rule for public goods or distorted from that level. When the quota is distorted from the efficient level it is set such that the aggregate marginal profit is less than the marginal damage, resulting in an overallocation of individual and aggregate quotas. However, efficient level of the quota is obtained in a reasonable special case in which countries take the role of the principals. The results are extended to cover tradable emission permits.
\end{abstract}

Keywords Environmental policy $\cdot$ Emissions trading $\cdot$ Common agency $\cdot$ Political economy · Quotas

JEL Classification $\mathrm{D} 72 \cdot \mathrm{H} 40 \cdot \mathrm{Q} 50$

\section{Introduction}

Political process determines the structure of environmental policy. This paper analyses the determination of the size of aggregate emission quota and its division between the polluters in a common agency framework. A set of principals can individually lobby a common agent to influence the aggregate size of the quota and subsequently for an increase in the slice of the quota each principal receives. The principals can be countries or firms, and the agent can be a regulator whose task it is to choose the policy structure. As a concrete example, this set-up can be used to describe lobbying related to effort sharing in the European Union's climate policy. The member states act as the principals who influence the European Commission

Pauli Lappi

pauli.lappi@helsinki.fi

1 University of Helsinki, Helsinki, Finland 
who decides the emission reduction target at the EU level and the sharing of individual emission reduction efforts.

The interaction between the agent and the principals is modeled with a two-stage game, where each stage consists of a menu auction game. In the first stage, every principal offers the agent a contribution schedule that is contingent on the size of the aggregate quota decided by the agent. Following this, the agent, who cares about the contribution and the social welfare the quota induces, chooses the aggregate quota. In the second stage of the game, given the chosen aggregate quota, every principal offers an additional contribution schedule to the agent, which is now contingent on the individual quota the principal receives. The agent then decides the division of the quota given that it cares about the profit/benefit of each principal and about the received contributions.

This paper finds that the political process distorts the size of the aggregate emission quota from the value satisfying the Samuelson's rule for the provision of public goods. Without lobbying, the aggregate quota, which is a public good for the principals, is set such that the aggregate marginal willingness to pay for the quota matches the marginal damage from it. Every principal uses its political influence to increase the size of the aggregate quota to be divided, and, after the quota has been set, to compete against the other principals in the division of the quota. Despite the apparent incentive to free-ride on the other principals' contributions for larger aggregate quota, every principal finds it in its interest to contribute. This is because the individual quota to be allocated in the second stage, and hence, the payoff is increasing in the aggregate quota. The end result is that both the aggregate quota and the individual allocations are excessive compared to the social optimum. These results are extended to the case where the quotas are tradable by adding a third stage to the above game, where the principals can trade the quotas given for free in stage two. An important exception to the overallocation result occurs in the case where the principals' aggregate emission damage equals the agent's damage. In this case, the aggregate and individual quotas match the social optimum. The reason for this is that each principal offers a marginal contribution to the agent that equals the difference between its marginal profit and marginal damage, which incentivizes the agent to choose the aggregate quota that maximizes social welfare.

This study contributes to the literature on the choice of environmental policy in a political process described by a common agency. ${ }^{1}$ This literature has covered international environmental agreements (Habla and Winkler 2013; Marchiori et al. 2017), international trade (Aidt 1998; Fredriksson 1997; Damania et al. 2003), overlapping geneneration models with an environmental tax (Karp and Rezai 2014), investment for clean technology (Grey 2018), corruption and environmental policy (Fredriksson and Svensson 2003) and the choice of emission tax and emission quota (Finkelshtain and Kislev 1997). The current paper focuses on endogenizing the choice of the aggregate quota and its division between lobbyists in the political

\footnotetext{
${ }^{1}$ Hence the political influence is direct in the form of political contributions as opposed to more indirect ways of influence like persuasion and communication as in Yu (2005) and in Bramoullé and Orset (2018).
} 
process with multiple principals or lobbyists. This is in contrast with Finkelshtain and Kislev (1997), whose model contains only one lobby group consisting of multiple polluters. This group lobbies for an emission vector that contains the quotas of the polluters. In their model, the lobbyist does not directly influence the aggregate quota. Here, there are multiple lobbyists who lobby both for the aggregate quota and its division. This results in a formula for the aggregate quota (the above-mentioned modification of the Samuelson's rule) and, as there are multiple lobbyists, in a competition for the individual quotas using the political influence. Relatedly, Lai (2007, 2008) also applies the common agency model, and focuses only on lobbying over the aggregate amount of (tradable) quotas and the decision to allocate the aggregate quota either by auctioning or grandfathering. ${ }^{2}$

The second stage of the model, the quota-division stage, has similarities with a model in Grossman and Helpman (2001), on pages 233-235, where the agent decides the division of a budget between two identical principals of which only one is organized as a lobby group. In that model, the organized principal obtains a larger quota compared to the equal division which is the outcome without lobbying. In the current model, there are multiple non-identical principals. In addition, the principals can use their political influence before the division stage when the agent sets the aggregate quota to be shared. Persson and Tabellini (1994) analyse the supply of local public goods that are financed at the federal level, and find that the supply of local public goods is larger under lobbying than under the decentralized solution. Here, the public good is global for the principals, and the principals can use their influence to change the supply decision of the aggregate quota and the allocation of the quota.

The study is organized as follows. Section 2 presents the model and the main results with a quota. This section also develops a special case with two principals. Section 3 extends the results to tradable quotas. Section 4 concludes.

\section{Quotas}

The menu auction framework of Bernheim and Whinston (1986) is used to model the common agency in both stages of the game. In both stages, the principals first make contributions to the agent that are contingent on the agent's choice (either the aggregate quota or its division) after which the agent maximizes its payoff. The agent chooses, at the first stage of the game, an aggregate quota $E$ and, at the second stage, distributes a quota share $e_{i}$ for every principal $i \in\{1, \ldots, N\}$ under the influence of the principals. The set of principals consists either of countries or firms, but the model and the results will be presented under the interpretation that the principals are countries. The necessary modifications to the model when principals are firms will be discussed when needed.

\footnotetext{
${ }^{2}$ Interestingly, however, Lai's lobbying model also includes an environmental group that can influence the choice over the aggregate quotas.
} 
Therefore, let the principals be countries. Each principal values its quota share according to the profit function $\pi_{i}$ that satisfies properties $\pi_{i}^{\prime}\left(e_{i}\right)>0$ and $\pi_{i}^{\prime \prime}\left(e_{i}\right)<0$, and pays the contributions it offers to the agent. In addition, each principal has preferences over the aggregate quota $E:=\sum_{i=1}^{N} e_{i}$, and these preferences are captured by the damage functions $D_{i}, i=1, \ldots, N$, with $D_{i}^{\prime}(E)>0$ and $D_{i}^{\prime \prime}(E) \geq 0$. The agent cares about the principals' profit and about the damages borne by them in its jurisdiction. In addition, the agent cares about the damages outside its jurisdiction captured by damage function $D_{0}$, with $D_{0}^{\prime}(E)>0$ and $D_{0}^{\prime \prime}(E) \geq 0$. The agent's damage function takes then the following form:

$$
D(E)=\sum_{i=1}^{N} D_{i}(E)+D_{0}(E),
$$

and satisfies $D^{\prime}(E)>0$ and $D^{\prime \prime}(E) \geq 0$. In addition to damages, the payoff to the agent consists of the principals' profits and contributions. ${ }^{3}$

However, when the principals are interpreted as firms, it is assumed that they suffer no damages from emissions. Therefore, the damage functions $D_{i}, i=1, \ldots, N$, are set in this case equal to zero. The damage function $D_{0}$ describes the damages suffered, for example, by the consumers in the agent's or regulator's jurisdiction.

The model is analyzed starting from the second stage. The aggregate quota $E$ is taken as given by the principals and the agent. The agent must decide an allocation or division of this quota between the principals. Every principal $i$ can influence this division by giving contributions to the agent that are contingent on the amount of quota the agent allocates to principal $i$. Thus, every principal acts individually in its lobbying efforts. The agent cares about the contributions the principals give and about the aggregate profit the principals obtain from the emission allocation. ${ }^{4}$ The objective of the agent is

$$
\sum_{i=1}^{N} C_{i}\left(e_{i}\right)+\alpha \sum_{i=1}^{N} \pi_{i}\left(e_{i}\right),
$$

where $\alpha \geq 0$ is a preference parameter, and function $C_{i}$ is the contribution schedule of principal $i$. At this stage, the aggregate quota is given, and the net profit for principal $i$ is the difference between the profit and the contribution, that is, $\pi_{i}\left(e_{i}\right)-C_{i}\left(e_{i}\right)$. The game proceeds as a menu auction game. First, the principals (lobby groups) offer contribution schedules to the agent. Second, given these schedules, the agent decides the division of the aggregate quota. The quota given for principal $i$ is assumed to belong to $\left[0, \bar{e}_{i}\right]$, where $\bar{e}_{i}$ is the baseline emissions for principal $i$. The equilibrium values are denoted with ${ }^{0}$-superscripts.

\footnotetext{
${ }^{3}$ The inclusion of $D_{0}$ only into the agent's damage function implies that the agent is altruistic in that it cares about damages occurring outside its jurisdiction, while the countries care only about their own damages.

${ }^{4}$ Note that the damages have no role in the allocation of the quota between the lobbyists because the pollution is uniform.
} 
Bernheim and Whinston (1986) show that an equilibrium exists, and they characterize all the equilibria of the type of menu auction used in either of the stages. In addition, they argue that there typically exists multiple equilibria. Their characterization result is taken as a definition here, and it is as follows: ${ }^{5}$

Definition 1 An allocation $\left(\left(e_{i}^{0}, C_{i}^{0}\right)_{i=1}^{N}\right)$, is a Nash equilibrium in the individual quota allocation-game if and only if

1. $C_{i}^{0} \geq 0$ for all $i=1, \ldots, N$,

2. $\left(e_{i}^{0}\right)_{i=1}^{N}$ maximizes

$$
\sum_{i=1}^{N} C_{i}^{0}\left(e_{i}\right)+\alpha \sum_{i=1}^{N} \pi_{i}\left(e_{i}\right)
$$

subject to $E=\sum_{i=1}^{N} e_{i}$,

3. $\left(e_{i}^{0}\right)_{i=1}^{N}$ maximizes

$$
\pi_{j}\left(e_{j}\right)-C_{j}^{0}\left(e_{j}\right)+\sum_{i=1}^{N} C_{i}^{0}\left(e_{i}\right)+\alpha \sum_{i=1}^{N} \pi_{i}\left(e_{i}\right),
$$

subject to $E=\sum_{i=1}^{N} e_{i}$, for all $j=1, \ldots, N$,

4. there exists a $\left(e_{i}^{-j}\right)_{i=1}^{N}$ that maximizes $\sum_{i=1}^{N} C_{i}^{0}\left(e_{i}\right)+\alpha \sum_{i=1}^{N} \pi_{i}\left(e_{i}\right)$ subject to $E=\sum_{i=1}^{N} e_{i}$, such that $C_{j}^{0}\left(e_{j}^{-j}\right)=0$ for every $j=1, \ldots, N$.

The first condition means that the contributions are feasible. The second says that the equilibrium allocation of quotas maximizes agent's payoff subject to the condition that total allocation equals the aggregate quota decided in the previous stage of the game. Third, it also maximizes the joint payoff of any principal and the agent under the same constraint. The final condition says that there exists, for each principal $j$, a quota allocation vector that gives the agent equal payoff as the equilibrium payoff but with principal $j$ contributing nothing.

Bernheim and Whinston (1986) also argue that there exists a subset of the equilibria called truthful equilibria, and it is these equilibria on which the applied literature has focused. The definition of a truthful contribution given by Bernheim and Whinston (1986), applied to the current context, says that a contribution schedule $C_{i}$ is truthful relative to agent's choice $\hat{e}_{i}$ if and only if for all $e_{i}$ either $(i)$

$$
\pi_{i}\left(e_{i}\right)-C_{i}\left(e_{i}\right)=\pi_{i}\left(\hat{e}_{i}\right)-C_{i}\left(\hat{e}_{i}\right),
$$

or (ii)

$$
\pi_{i}\left(e_{i}\right)-C_{i}\left(e_{i}\right)<\pi_{i}\left(\hat{e}_{i}\right)-C_{i}\left(\hat{e}_{i}\right) \quad \text { and } \quad C_{i}\left(e_{i}\right)=0 \text {. }
$$

\footnotetext{
${ }^{5}$ In the definition, $e_{i}^{0}$, s are numbers, and $C_{i}^{0}$ 's are functions.
} 
In addition, a collection of quotas and contributions $\left(\left(e_{i}^{0}, C_{i}^{0}\right)_{i=1}^{N}\right)$ is called a truthful Nash equilibrium if and only if it is a Nash equilibrium, and $C_{i}^{0}$ is truthful relative to $e_{i}^{0}$ for each principal $i$.

Equation (5) implies that $C_{i}^{\prime}\left(e_{i}\right)=\pi_{i}^{\prime}\left(e_{i}\right)$ for all $e_{i}$ for which $C_{i}\left(e_{i}\right)>0$. Therefore, the contribution of principal $i$ in a truthful Nash equilibrium is differentiable everywhere except at a point for which $C_{i}=0$, and every neighbourhood of the point contains other points with $C_{i}>0$. In addition, the graph of $C_{i}$ has the same shape as the graph of $\pi_{i}$ whenever contribution is strictly positive.

Proposition 1 Suppose that the agent divides an aggregate quota E betweenN principals who all act as lobby groups. Then, in a truthful Nash equilibrium with interior quotas for each group and strictly positive contributions, the groups' quotas and contributions satisfy the following conditions:

(i) $\quad\left(e_{i}^{0}\right)_{i=1}^{N}$ satisfies equations $\pi_{k}^{\prime}\left(e_{k}\right)=\pi_{j}^{\prime}\left(e_{j}\right)$ for all $k$ and $j$, and $\sum_{i=1}^{N} e_{i}=E$,

(ii) the contribution schedule of principal $i$ is

$$
\begin{aligned}
C_{i}^{0}\left(e_{i}\right)= & -\int_{e_{i}}^{e_{i}^{0}} \pi_{i}^{\prime}(\tau) \mathrm{d} \tau+\sum_{\substack{j=1 \\
j \neq i}}^{N}\left(C_{j}^{0}\left(e_{j}^{-i}\right)-C_{j}^{0}\left(e_{j}^{0}\right)\right) \\
& +\alpha\left(\sum_{j=1}^{N} \pi_{j}\left(e_{j}^{-i}\right)-\sum_{j=1}^{N} \pi_{j}\left(e_{j}^{0}\right)\right),
\end{aligned}
$$

for all $i=1, \ldots, N$.

Proof See Appendix A.1.

Part (i) shows that the allocation of individual emission quotas between the principals is the same as when the principals do not participate in the lobbying activity, that is, the emission allocation under lobbying solves the problem $\max _{\left(e_{i}\right)_{i}^{N}}\left\{\sum_{i=1}^{N} \pi_{i}\left(e_{i}\right)\right\}$ subject to the constraint $E=\sum_{i=1}^{N} e_{i}$. Thus, the marginal profits are equalized across principals. This is expected as the agent weights the contributions and the emission profits of different principals in the same way using parameter $\alpha$. If, somehow, the principals were able to coordinate their actions, and agree that none of them contributes anything, they would achieve the same emission quota allocation as above. However, as this is not feasible, every principal reasons that it is in the best interest of the principal to contribute since others contribute. The equilibrium individual quota for principal $i$ depends on $E$ and solves $\pi_{N}^{\prime}\left(E-\sum_{i=1}^{N-1} e_{i}\right)-\pi_{i}^{\prime}\left(e_{i}\right)=0$. Denote it with $e_{i}(E)$. It can be shown that $\mathrm{d} e_{i} / \mathrm{d} E>0$ (see Appendix A.2). Hence, as intuition suggests, from the profit perspective the principals would like the aggregate quota to be as large as possible because their profits increase in the aggregate quota. 
If there is only one principal, then that principal does not need to lobby at all at this stage, since it receives the whole cake anyway. But, as there are multiple lobbyists, the purpose of giving contributions to the agent is to guarantee that the agent has no incentives to deviate from the allocation that maximizes the aggregate profits of the lobbyists. In equilibrium, the contribution of principal $i$ is

$$
C_{i}^{0}\left(e_{i}^{0}\right)=\sum_{\substack{j=1 \\ j \neq i}}^{N}\left(C_{j}^{0}\left(e_{j}^{-i}\right)-C_{j}^{0}\left(e_{j}^{0}\right)\right)+\alpha\left(\sum_{j=1}^{N} \pi_{j}\left(e_{j}^{-i}\right)-\sum_{j=1}^{N} \pi_{j}\left(e_{j}^{0}\right)\right) .
$$

In order to rewrite the equilibrium contribution of principal $i$, take principal $j$ in Part (ii) of Proposition 1 and plug $e_{j}=e_{j}^{-i}$ into its equilibrium contribution function. Subtracting the equilibrium value of the contribution from it gives

$$
C_{j}^{0}\left(e_{j}^{-i}\right)-C_{j}^{0}\left(e_{j}^{0}\right)=\pi_{j}\left(e_{j}^{-i}\right)-\pi_{j}\left(e_{j}^{0}\right) \text { for any } j \neq i .
$$

Therefore the equilibrium contribution for principal $i$ can be rewritten as

$$
C_{i}^{0}\left(e_{i}^{0}\right)=\sum_{\substack{j=1 \\ j \neq i}}^{N} \pi_{j}\left(e_{j}^{-i}\right)+\alpha \sum_{j=1}^{N} \pi_{j}\left(e_{j}^{-i}\right)-\left(\sum_{\substack{j=1 \\ j \neq i}}^{N} \pi_{j}\left(e_{j}^{0}\right)+\alpha \sum_{j=1}^{N} \pi_{j}\left(e_{j}^{0}\right)\right) .
$$

The contribution of principal $i$ equals the difference between the joint profit of the other lobby groups and the agent when principal $i$ does not contribute and when it contributes. This conclusion is similar with the two lobby case in (Grossman and Helpman (1994), Example 2). ${ }^{6}$

The analysis now proceeds to Stage 1, where the principals first give contributions to the agent that are contingent on the size of the aggregate quota. The agent then chooses the quota in order to maximize its payoff. Let principal $i$ 's profit, as a function of the aggregate quota, be $\Pi_{i}(E):=\pi_{i}\left(e_{i}(E)\right)$ and assume that $\Pi_{i}^{\prime \prime}<0 .^{7}$ The payoff for principal $i$ is

$$
\Pi_{i}(E)-D_{i}(E)-K_{i}(E),
$$

where $K_{i}$ is the contribution schedule. Define the social welfare obtained from the quota with

\footnotetext{
${ }^{6}$ In general, a menu auction model could have multiple truthful equilibria. Uniqueness is shown in Appendix A.3 in a special case with two principals using the results from Laussel and Le Breton (2001) and Bergemann and Välimäki (2003). This special case is further investigated after studying Stage 1.

7 A sufficient condition for this is that $\pi_{i}$ is a quadratic function (as then $\mathrm{d} e_{i} / \mathrm{d} E$ is a constant).
} 


$$
W(E):=\sum_{i=1}^{N} \Pi_{i}(E)-D(E)
$$

and the agent's payoff with

$$
\sum_{i=1}^{N} K_{i}(E)+\alpha W(E)
$$

Like in the previous stage, a result from Bernheim and Whinston (1986) is applied as a definition in order to characterize the equilibrium:

Definition 2 An allocation $\left(E^{0},\left(K_{i}^{0}\right)_{i=1}^{N}\right)$, is a Nash equilibrium in the aggregate quota-game if and only if

1. $K_{i}^{0} \geq 0$ for all $i=1, \ldots, N$,

2. $E^{0}$ maximizes

$$
\sum_{i=1}^{N} K_{i}^{0}(E)+\alpha\left(\sum_{i=1}^{N} \Pi_{i}(E)-D(E)\right)
$$

3. $E^{0}$ maximizes

$$
\Pi_{j}(E)-D_{j}(E)-K_{j}^{0}(E)+\sum_{i=1}^{N} K_{i}^{0}(E)+\alpha\left(\sum_{i=1}^{N} \Pi_{i}(E)-D(E)\right),
$$

for all $j=1, \ldots, N$,

4. there exists a $E^{-j}$ that maximizes $\sum_{i=1}^{N} K_{i}^{0}(E)+\alpha\left(\sum_{i=1}^{N} \Pi_{i}(E)-D(E)\right)$, such that $K_{j}^{0}\left(E^{-j}\right)=0$ for every $j=1, \ldots, N$.

The interpretation of these conditions is similar to the previous definition and is omitted. Truthful Nash equilibrium is defined in a similar way as in Stage 2.

Proposition 2 Suppose that the agent sets the aggregate quota for the principals who all act as lobby groups. Then, in a truthful Nash equilibrium with an interior aggregate quota and strictly positive contributions, the aggregate quota and the contributions satisfy the following conditions:

(i) $E^{0}$ satisfies equation

$$
\sum_{i=1}^{N} \Pi_{i}^{\prime}(E)-D^{\prime}(E)=-\frac{1}{\alpha} \sum_{i=1}^{N}\left(\Pi_{i}^{\prime}(E)-D_{i}^{\prime}(E)\right) .
$$

(ii) the contribution schedule of principal i is 


$$
\begin{aligned}
K_{i}^{0}(E)= & -\int_{E}^{E^{0}}\left(\Pi_{i^{\prime}}(\tau)-D_{i^{\prime}}(\tau)\right) d \tau+\sum_{\substack{j=1 \\
j \neq i}}^{N}\left(K_{j}^{0}\left(E^{-i}\right)-K_{j}^{0}\left(E^{0}\right)\right) \\
& +\alpha\left(W\left(E^{-i}\right)-W\left(E^{0}\right)\right),
\end{aligned}
$$

for all $i=1, \ldots, N$.

Proof See Appendix A.4.

The aggregate quota is essentially a public good for the principals (countries). Equation (15) governs its allocation when every principal on the demand side, enjoying the good, acts as a lobby group with an interest to influence the provision. Without lobbying one obtains the Samuelson's rule stating that the aggregate marginal profit from the quota, or the marginal willingness to pay, equals the marginal damages from it. Note that the terms $\sum_{i=1}^{N} \Pi_{i}^{\prime}(E)-D^{\prime}(E)$ and $\sum_{i=1}^{N}\left(\Pi_{i}^{\prime}(E)-D_{i}^{\prime}(E)\right)$ have opposite signs, and that inequality $D^{\prime}(E)>\sum_{i=1}^{N} D_{i}^{\prime}(E)$ implies then that inequality $\sum_{i=1}^{N} \Pi_{i}^{\prime}(E)-D^{\prime}(E)<0$ holds. Equation (15) shows therefore that when the principals engage in lobbying the difference between the aggregate marginal profit and marginal damage is strictly negative. Hence, the equilibrium quota is excessive compared to the social optimum obtained from the Samuelson's rule.

However, an important corollary of this result is obtained in the special case where the agent's damage function $D$ equals the sum of the principals' damage functions:

Corollary 1 When the principals are countries and the agent's damage function equals the aggregate damage of the principals (i.e., $\left.D_{0}(E)=0\right)$, the aggregate quota is set at the efficient level.

This case is a reasonable description, and it implies that both the aggregate and the individual quotas are at their socially optimal levels. The reason for this is that the equilibrium marginal contribution of principal $i$ equals the difference between $i$ 's marginal profit and marginal damage. This implies that the aggregate marginal contribution equals the sum of the difference between marginal profits and marginal damages. Because the agent cares about the aggregate contribution and the social welfare, and because these are at the margin the same in equilibrium, the agent chooses the aggregate quota as if to maximize the social welfare. Hence, the efficiency result is obtained.

The overallocation result of Proposition 2 holds in particular when the principals are firms. In this case, the equilibrium aggregate quota satisfies equation

$$
\sum_{i=1}^{N} \Pi_{i}^{\prime}(E)-D^{\prime}(E)=-\frac{1}{\alpha} \sum_{i=1}^{N} \Pi_{i}^{\prime}(E) .
$$


because the marginal damages $D_{i}^{\prime}$ are dropped from the above result. Using equation $\left.\pi_{k}^{\prime}\left(e_{k}(E)\right)\right)=\pi_{j}^{\prime}\left(e_{j}(E)\right)$ for every $k$ and $j$ (from Proposition 1), Equation (15) can be rewritten as

$$
\pi_{i}^{\prime}\left(e_{i}(E)\right)-D^{\prime}(E)=-\frac{1}{\alpha} \pi_{i}^{\prime}\left(e_{i}(E)\right),
$$

which is the same condition as the one in the result on the allocation of individual quotas presented in Finkelshtain and Kislev (1997). ${ }^{8}$ In their model, the lobby group consists of multiple polluters, and this group exerts lobbying effort to influence the agent's choice over the individual quotas given to the polluters. Here the polluters act individually in their lobbying efforts and the individual quotas depend on the aggregate size of the quota, which is also under political pressure. Equation (17) says that the aggregate quota is set such that the difference between the marginal profit from individual quota and the marginal damage is strictly negative for any of the principals. Hence, there is an overallocation of individual quotas compared to the social optimum where marginal profit equals marginal damages. Interestingly, because (17) matches the condition in Finkelshtain and Kislev (1997), the size of the aggregate quota and its allocation between the firms is the same in the models.

Applying the implicit function theorem to Equation (15) gives

$$
\frac{\mathrm{d} E}{\mathrm{~d} \alpha}=-\frac{\sum_{i=1}^{N} \Pi_{i}^{\prime}(E)-D^{\prime}(E)}{\sum_{i=1}^{N}\left(\Pi_{i}^{\prime \prime}(E)-D_{i}^{\prime \prime}(E)\right)+\alpha\left(\sum_{i=1}^{N} \Pi_{i}^{\prime \prime}(E)-D^{\prime \prime}(E)\right)}<0,
$$

which means that the less the agent cares about social welfare, the larger will be the quota, and the greater will be the difference between the equilibrium quota and the social optimum. In addition, as the individual quotas are $e_{i}(E)$, the above implies that

$$
\frac{\mathrm{d} e_{i}}{\mathrm{~d} \alpha}=\frac{\mathrm{d} e_{i}}{\mathrm{~d} E} \frac{\mathrm{d} E}{\mathrm{~d} \alpha}<0 .
$$

As with the aggregate quota, the individual quotas are larger if the agent cares less about the social welfare (or the benefits to the principals).

This section is concluded with a special case of two principals using a linearquadratic specification often applied in the international environmental agreements literature including for example Barrett (1994) and Marchiori et al. (2017). ${ }^{9}$ This special case illustrates how asymmetry between the principals affects the equilibrium quotas. Let there be two principals (countries) with payoff functions $\pi_{i}\left(e_{i}\right)=\bar{\pi}_{i}-\left(c_{i} / 2\right)\left(\bar{e}_{i}-e_{i}\right)^{2}$ where $\bar{\pi}_{i}>0, c_{i}>0$ and $\bar{e}_{i}>0$. Let the principals' damage functions be $D_{1}(E)=d_{1} E$ and $D_{2}(E)=d_{2} E$, and let the damages outside

\footnotetext{
${ }^{8}$ A difference in the models is that in their model the aggregate contribution is multiplied by the preference parameter $\alpha$.

9 It is shown in Appendix A.5 that the stage 1 truthful equilibrium is unique.
} 
the agent's jurisdiction be $D_{0}(E)=d_{0} E$. The agent's damage from quota is then $D(E)=d_{0} E+d_{1} E+d_{2} E$. The equilibrium quotas given to the principals are

$$
\left(e_{1}^{0}, e_{2}^{0}\right)=\left(\bar{e}_{1}-\frac{\alpha}{1+\alpha} \frac{d_{0}}{c_{1}}-\frac{d_{1}+d_{2}}{c_{1}}, \bar{e}_{2}-\frac{\alpha}{1+\alpha} \frac{d_{0}}{c_{2}}-\frac{d_{1}+d_{2}}{c_{2}}\right),
$$

and the equilibrium aggregate quota is

$$
E^{0}=\bar{E}-d_{0} \frac{\alpha}{1+\alpha} \frac{c_{1}+c_{2}}{c_{1} c_{2}}-\left(d_{1}+d_{2}\right) \frac{c_{1}+c_{2}}{c_{1} c_{2}} .
$$

Details on the calculations are presented in Appendix A.6. The interesting parameters are the marginal damage parameters, $d_{i}, i=0,1,2$, and the slope parameters, $c_{1}$ and $c_{2}$, of the marginal profit functions (or the marginal abatement costs). Notice that the individual quotas and the aggregate quota are lower for higher marginal damage parameters. Also, the quotas depend on the sum of principals' damage parameters $d_{1}$ and $d_{2}$, but the effect of an increase in one of these parameters is asymmetrical: an increase in principal $i$ 's damage parameter $d_{i}$ has a larger effect on the quota of the principal that has a lower slope parameter. In other words, greater emission induced harm implies that the quota decreases more for the principal to whom it is less costly to decrease emissions.

\section{Tradable quotas}

Similar overallocation of individual and aggregate quotas occurs also when the distributed quotas are tradable among the principals. The principals lobby in the first stage of the game over the total amount of emission permits (i.e., aggregate quota). In the second stage, the principals lobby over the initial allocations of permits given for free to each principal (i.e., individual quotas). The difference in the game structure compared to the non-tradable quotas is the market for permits in which the principals can trade their permits after the second stage of the game. Hence, the third stage is described by a competitive equilibrium in the permit market.

Let $E$ be the aggregate quota and $e_{i}$ be the share of it given for free to principal $i$. The principal values it according to the payoff function $\pi_{i}$, which is the value function of principal's third stage problem. ${ }^{10}$ Clearly, the reasoning used in Proposition 1 can be applied also for tradable quotas, and hence $\pi_{k}^{\prime}\left(e_{k}\right)=\pi_{j}^{\prime}\left(e_{j}\right)$ for all principals $k$ and $j$. As the marginal valuation is given by equation $\pi_{i}^{\prime}\left(e_{i}\right)=p$, where $p$ is the permit price, the equilibrium permit price is characterized by the following result:

Proposition 3 Suppose that the agent sets an aggregate quota and distributes it for free to the principals who all act as lobby groups and who are allowed to trade their emission quotas. Then, in a truthful Nash equilibrium with an interior aggregate

\footnotetext{
10 That is, $\pi_{i}\left(e_{i}\right):=\max _{\left\{z_{i}\right\}}\left\{b_{i}\left(z_{i}\right)-p\left(z_{i}-e_{i}\right)\right\}$, where $z_{i}$ are principal's emissions, $b_{i}$ is the profit function and $p$ is the permit price.
} 
quota and strictly positive contributions, the equilibrium permit price $p^{0}$ satisfies equation

$$
p-D^{\prime}(E)=-\frac{1}{\alpha}\left(p-\sum_{i=1}^{N} D_{i}(E)\right) .
$$

Proof The proof is similar to the ones related to non-tradable quotas and is omitted.

Lobbying over the total amount of emission permits and their free allocation drives a wedge between the price of permits and the marginal damages from emissions, and this wedge is given by the right-side of Equation (22). Hence, the price is strictly lower than the marginal damages compared to the case without lobbying. It follows that both the total amount of emissions and the free allocation for every principal is larger in a lobbying equilibrium compared to social optimum. If the permits are auctioned instead of given away for free, the model simplifies to one with lobbying over the aggregate quota followed by the auction. As long as the marginal payoffs $\pi_{i}^{\prime}$ are equalized with the price for each principal, Equation (22) continues to characterize the equilibrium price.

\section{Conclusion}

This paper showed how the aggregate emission quota and its individual allocations are distorted from the social optimum in a political economy model, in which a set of special interest groups or principals (either firms or countries) influence a common agent. When the principals are firms who have no preferences over emission damages, the aggregate emission quota is excessive compared to the value given by the Samuelson's rule, and the individual quotas are all larger than their socially optimal counterparts. This result also holds when the principals are countries, who suffer damages from aggregate emissions, except when the agent's and the principals' aggregate damages are equal. As a practical example, lobbying is a distinctive feature of the formation of the European Union's climate policy. When the principals are interpreted as member states and the agent as the European Commission, the results show, except for the above case, that both the EU-wide target level for emission reduction and the distribution of the emission reduction efforts across the member states are excessive compared to the situation without lobbying.

\section{Appendix}

\section{Proof of proposition 1}

Part (i): Definition 1 (Part (2)) implies that $\left(e_{i}^{0}\right)_{i=1}^{N}$ satisfies equation 


$$
C_{i}^{0 \prime}\left(e_{i}\right)-C_{N}^{0 \prime}\left(E-\sum_{i=1}^{N-1} e_{i}\right)+\alpha\left(\pi_{i}^{\prime}\left(e_{i}\right)-\pi_{N}^{\prime}\left(E-\sum_{i=1}^{N-1} e_{i}\right)\right)=0
$$

for all $i \neq N$. Part (3), which involves $N$ different constrained maximization problems, implies that $\left(e_{i}^{0}\right)_{i=1}^{N}$ satisfies, for any $j \neq N$, equations

$$
\begin{gathered}
\pi_{j}^{\prime}\left(e_{j}\right)-C_{N}^{0 \prime}\left(E-\sum_{i=1}^{N-1} e_{i}\right)+\alpha\left(\pi_{j}^{\prime}\left(e_{j}\right)-\pi_{N}^{\prime}\left(E-\sum_{i=1}^{N-1} e_{i}\right)\right)=0, \quad \text { (A. } \\
C_{i}^{0 \prime}\left(e_{i}\right)-C_{N}^{0 \prime}\left(E-\sum_{i=1}^{N-1} e_{i}\right)+\alpha\left(\pi_{i}^{\prime}\left(e_{i}\right)-\pi_{N}^{\prime}\left(E-\sum_{i=1}^{N-1} e_{i}\right)\right)=0, \quad \text { for all } i \neq j,
\end{gathered}
$$

and, for $j=N$

$$
-\pi_{N}^{\prime}\left(E-\sum_{i=1}^{N-1} e_{i}\right)+C_{i}^{0 \prime}\left(e_{i}\right)+\alpha\left(\pi_{i}^{\prime}\left(e_{i}\right)-\pi_{N}^{\prime}\left(E-\sum_{i=1}^{N-1} e_{i}\right)\right)=0, \quad \text { for all } i \neq N .
$$

Solving for $C_{N}^{0 \prime}\left(E-\sum_{i=1}^{N-1} e_{i}\right)$ and $C_{i}^{0 \prime}\left(e_{i}\right)$ from equations (A.2) and (A.4) gives

$$
\begin{gathered}
C_{N}^{0 \prime}\left(E-\sum_{i=1}^{N-1} e_{i}\right)=\pi_{i}^{\prime}\left(e_{i}\right)+\alpha\left(\pi_{i}^{\prime}\left(e_{i}\right)-\pi_{N}^{\prime}\left(E-\sum_{i=1}^{N-1} e_{i}\right)\right), \\
C_{i}^{0 \prime}\left(e_{i}\right)=\pi_{N}^{\prime}\left(E-\sum_{i=1}^{N-1} e_{i}\right)-\alpha\left(\pi_{i}^{\prime}\left(e_{i}\right)-\pi_{N}^{\prime}\left(E-\sum_{i=1}^{N-1} e_{i}\right)\right),
\end{gathered}
$$

which both hold for any $i \neq N$. Plugging these into Equation (A.1) gives equation $-\left(\pi_{i}^{\prime}\left(e_{i}\right)-\pi_{N}^{\prime}\left(E-\sum_{i=1}^{N-1} e_{i}\right)\right)-\alpha\left(\pi_{i}^{\prime}\left(e_{i}\right)-\pi_{N}^{\prime}\left(E-\sum_{i=1}^{N-1} e_{i}\right)\right)=0$, from which the result follows (as $\alpha \geq 0$ ).

Part (ii): Equations (A.1) and (A.2) imply $C_{i}^{0 \prime}\left(e_{i}\right)=\pi_{i}^{\prime}\left(e_{i}\right)$ for all $i \neq N$, and equations (A.1), (A.4) and $E=\sum_{i=1}^{N} e_{i}$ imply $C_{N}^{0 \prime}\left(e_{N}\right)=\pi_{N}^{\prime}\left(e_{N}\right)$. As the contribution schedules are assumed truthful, these equations hold for each quota level with strictly positive contribution and give for every $i$ schedules of the form

$$
C_{i}^{0}\left(e_{i}\right)=\int_{e_{i+}}^{e_{i}} \pi_{i}^{\prime}(\tau) \mathrm{d} \tau+k_{i}
$$

for some constant $k_{i}$ and emission level $e_{i+}$ (the largest emission level for which the contribution is zero). To determine $k_{i}$ 's note that by Part (2) and Part (4) of Definition 1 , there exists for every $i$ a $\left(e_{j}^{-i}\right)_{j=1}^{N}$ such that 


$$
\sum_{\substack{j=1 \\ j \neq i}}^{N} C_{j}^{0}\left(e_{j}^{-i}\right)+\alpha \sum_{j=1}^{N} \pi_{j}\left(e_{j}^{-i}\right)=\sum_{j=1}^{N} C_{j}^{0}\left(e_{j}^{0}\right)+\alpha \sum_{j=1}^{N} \pi_{j}\left(e_{j}^{0}\right) .
$$

This implies

$$
C_{i}^{0}\left(e_{i}^{0}\right)=\sum_{\substack{j=1 \\ j \neq i}}^{N}\left(C_{j}^{0}\left(e_{j}^{-i}\right)-C_{j}^{0}\left(e_{j}^{0}\right)\right)+\alpha\left(\sum_{j=1}^{N} \pi_{j}\left(e_{j}^{-i}\right)-\sum_{j=1}^{N} \pi_{j}\left(e_{j}^{0}\right)\right) .
$$

Then

$$
k_{i}=-\int_{e_{i}+}^{e_{i}^{0}} \pi_{i}^{\prime}(\tau) \mathrm{d} \tau+\sum_{\substack{j=1 \\ j \neq i}}^{N}\left(C_{j}^{0}\left(e_{j}^{-i}\right)-C_{j}^{0}\left(e_{j}^{0}\right)\right)+\alpha\left(\sum_{j=1}^{N} \pi_{j}\left(e_{j}^{-i}\right)-\sum_{j=1}^{N} \pi_{j}\left(e_{j}^{0}\right)\right),
$$

and hence

$$
C_{i}^{0}\left(e_{i}\right)=-\int_{e_{i}}^{e_{i}^{0}} \pi_{i^{\prime}}(\tau) d \tau+\sum_{\substack{j=1 \\ j \neq i}}^{N}\left(C_{j}^{0}\left(e_{j}^{-i}\right)-C_{j}^{0}\left(e_{j}^{0}\right)\right)+\alpha\left(\sum_{j=1}^{N} \pi_{j}\left(e_{j}^{-i}\right)-\sum_{j=1}^{N} \pi_{j}\left(e_{j}^{0}\right)\right)
$$

\section{Calculation of $\mathrm{de} i \mathrm{dE}$}

Equation $\pi_{i}^{\prime}\left(e_{i}\right)-\pi_{N}^{\prime}\left(E-\sum_{i=1}^{N-1} e_{i}\right)=0$ for $i \neq N$ implies that

$$
\left(\pi_{i}^{\prime \prime}\left(e_{i}\right)+\pi_{N}^{\prime \prime}\left(e_{N}\right)\right) \frac{\mathrm{d} e_{i}}{\mathrm{~d} E}+\sum_{\substack{j=1 \\ j \neq i}}^{N-1} \pi_{N}^{\prime \prime}\left(e_{N}\right) \frac{\mathrm{d} e_{j}}{\mathrm{~d} E}=\pi_{N}^{\prime \prime}\left(e_{N}\right)
$$

and equations $\pi_{i}^{\prime}\left(e_{i}\right)=\pi_{j}^{\prime}\left(e_{j}\right)$ for all $i$ and for all $j$ that

$$
\frac{\mathrm{d} e_{j}}{\mathrm{~d} E}=\frac{\pi_{i}^{\prime \prime}\left(e_{i}\right)}{\pi_{j}^{\prime \prime}\left(e_{j}\right)} \frac{\mathrm{d} e_{i}}{\mathrm{~d} E} \text { for all } i, j .
$$

Plugging the latter ones into the former, gives

$$
\frac{\mathrm{d} e_{i}}{\mathrm{~d} E}=\frac{\pi_{N}^{\prime \prime}\left(e_{N}\right)}{\pi_{i}^{\prime \prime}\left(e_{i}\right)+\pi_{N}^{\prime \prime}\left(e_{N}\right)+\sum_{\substack{j=1 \\ j \neq i}}^{N-1} \pi_{N}^{\prime \prime}\left(e_{N}\right) \frac{\pi_{i}^{\prime \prime}\left(e_{i}\right)}{\pi_{j}^{\prime \prime}\left(e_{j}\right)}}>0, \quad \text { for } i \neq N .
$$


For the principal $N$, Equation $\pi_{i}^{\prime}\left(e_{i}\right)=\pi_{N}^{\prime}\left(e_{N}\right)$ and (A.14) imply that

$$
\frac{\mathrm{d} e_{N}}{\mathrm{~d} E}=\frac{\pi_{i}^{\prime \prime}\left(e_{i}\right)}{\pi_{i}^{\prime \prime}\left(e_{i}\right)+\pi_{N}^{\prime \prime}\left(e_{N}\right)+\sum_{\substack{j=1 \\ j \neq i}}^{N-1} \pi_{N}^{\prime \prime}\left(e_{N}\right) \frac{\pi_{i}^{\prime \prime}\left(e_{i}\right)}{\pi_{j}^{\prime \prime}\left(e_{j}\right)}}>0 .
$$

\section{Uniqueness of the stage 2 equilibrium with $N=2$}

Proposition 4 Suppose that $N=2$. The truthful equilibrium of the quota division stage is unique.

Proof Let $\Gamma$ be the set of all principals, $S \subset \Gamma$ and $-S:=\Gamma \backslash S$. Define the maximized joint payoff of the principals in $S$ and the agent as

$$
\mathcal{W}_{S}:=\max _{\left\{e_{1}, \ldots, e_{N}, \sum e_{i}=E\right\}}\left\{\sum_{i \in S} \pi_{i}\left(e_{i}\right)+\alpha \sum_{i \in \Gamma} \pi_{i}\left(e_{i}\right)\right\},
$$

Laussel and Breton (2001) and Bergemann and Välimäki (2003) show that the following condition is sufficient for the uniqueness of the truthful Nash equilibrium: for all subsets $S$ and $T$ of $\Gamma$ with $S \cap T=\emptyset$,

$$
\mathcal{W}_{\Gamma}-\mathcal{W}_{-S}-\mathcal{W}_{-T}+\mathcal{W}_{-(S \cup T)} \leq 0
$$

Note that for $S=\Gamma$ and for $S=\emptyset$ the optimal emissions in (A.16) are the same (but that $\left.\mathcal{W}_{\Gamma}>\mathcal{W}_{\emptyset}\right)$. Denote these emissions with $e_{i, *}$ for each $i$. Then

$$
\mathcal{W}_{\Gamma}=(1+\alpha) \sum_{i \in \Gamma} \pi_{i}\left(e_{i, *}\right)
$$

To rewrite $\mathcal{W}_{-S}$, let $e_{i, S}$ be the optimal emissions for principals in $S$ and $e_{i,-S}$ be the optimal emissions for principals in $-S$. Then

$$
\mathcal{W}_{-S}=(1+\alpha) \sum_{i \in-S} \pi_{i}\left(e_{i,-S}\right)+\alpha \sum_{i \in S} \pi_{i}\left(e_{i, S}\right)
$$

Assume first that one of the sets $S$ or $T$ is the empty set. Let it be $S$. Then $\mathcal{W}_{-(S \cup T)}=\mathcal{W}_{-T}$, and therefore (A.17) becomes $\mathcal{W}_{\Gamma}-\mathcal{W}_{-S} \leq 0$, which is true because $\mathcal{W}_{-S}=\mathcal{W}_{\Gamma}$. Suppose then that $S, T \neq \emptyset$ and $S \cap T=\emptyset$ (hence both sets have a single principal in them). In this case $-(S \cup T)=\emptyset$, which implies

$$
\mathcal{W}_{-(S \cup T)}=\alpha \sum_{i \in \Gamma} \pi_{i}\left(e_{i, *}\right)
$$

Let principal 1 belong to $-S$. Then the left-side of (A.17) can be written as 


$$
\begin{gathered}
(1+\alpha) \sum_{i \in \Gamma} \pi_{i}\left(e_{i, *}\right)-(1+\alpha) \pi_{1}\left(e_{1,-S}\right)-\alpha \pi_{2}\left(e_{2, S}\right) \\
-(1+\alpha) \pi_{2}\left(e_{2,-T}\right)-\alpha \pi_{1}\left(e_{1, T}\right)+\alpha \sum_{i \in \Gamma} \pi_{i}\left(e_{i, *}\right) .
\end{gathered}
$$

Definition in (A.16) implies that

$$
(1+\alpha) \pi_{1}\left(e_{1,-S}\right)+\alpha \pi_{2}\left(e_{2, S}\right) \geq(1+\alpha) \pi_{1}\left(e_{1, *}\right)+\alpha \pi_{2}\left(e_{2, *}\right),
$$

and

$$
(1+\alpha) \pi_{2}\left(e_{2,-T}\right)+\alpha \pi_{1}\left(e_{1, T}\right) \geq(1+\alpha) \pi_{2}\left(e_{2, *}\right)+\alpha \pi_{1}\left(e_{1, *}\right) .
$$

These can be used to evaluate (A.22) upwards as

$$
\begin{aligned}
& \leq(1+\alpha) \sum_{i \in \Gamma} \pi_{i}\left(e_{i, *}\right)-(1+\alpha) \pi_{1}\left(e_{1, *}\right)-\alpha \pi_{2}\left(e_{2, *}\right) \\
& -(1+\alpha) \pi_{2}\left(e_{2, *}\right)-\alpha \pi_{1}\left(e_{1, *}\right)+\alpha \sum_{i \in \Gamma} \pi_{i}\left(e_{i, *}\right)=0 .
\end{aligned}
$$

Hence the truthful equilibrium is unique.

\section{Proof of proposition 2}

Part (i): Part (2) of Definition 2 implies that

$$
\sum_{i=1}^{N} K_{i}^{0 \prime}(E)+\alpha\left(\sum_{i=1}^{N} \Pi_{i}^{\prime}(E)-D^{\prime}(E)\right)=0,
$$

and Part (3) that for all $j$

$$
\Pi_{j}^{\prime}(E)-D_{j}^{\prime}(E)-K_{j}^{0 \prime}(E)+\sum_{i=1}^{N} K_{i}^{0 \prime}(E)+\alpha\left(\sum_{i=1}^{N} \Pi_{i}^{\prime}(E)-D^{\prime}(E)\right)=0 .
$$

Together these imply that $\Pi_{j}^{\prime}(E)-D_{j}^{\prime}(E)=K_{j}^{0 \prime}(E)$ for all $j$. The desired equation follows from (A.27).

Part (ii): The proof is similar to the proof of the second part of Proposition 1 and is omitted.

\section{Uniqueness of the stage 1 equilibrium with $N=2$}

Proposition 5 Suppose that $N=2$. The truthful equilibrium of the aggregate quota stage is unique. 


\section{Proof Define}

$$
\mathcal{M}_{S}:=\max _{\{E\}}\left\{\sum_{i \in S}\left(\Pi_{i}(E)-D_{i}(E)\right)+\alpha\left(\sum_{i \in \Gamma} \Pi_{i}(E)-D(E)\right)\right\} .
$$

Denote the maximizer with $E_{S}$ for all non-empty sets, and with $E_{*}$ for the empty set. It will be shown that the inequality

$$
2 \mathcal{M}_{\Gamma}-\mathcal{M}_{-S}-\mathcal{M}_{-T}-\mathcal{M}_{\Gamma}+\mathcal{M}_{-(S \cup T)} \leq 0,
$$

holds for all $S, T \subset \Gamma, S \cap T=\emptyset$.

Suppose that $S=\emptyset$. Then $\mathcal{M}_{-(S \cup T)}=\mathcal{M}_{-T}$ and $\mathcal{M}_{-S}=\mathcal{M}_{\Gamma}$, which implies that (A.30) holds as an equality. Suppose then that $S, T \neq \emptyset$ and $S \cap T=\emptyset$. Define

$$
P_{S}(E):=\sum_{i \in S}\left(\Pi_{i}(E)-D_{i}(E)\right)
$$

and recall that $W(E)=\sum_{i \in \Gamma} \Pi_{i}(E)-D(E)$. Then

$$
\begin{gathered}
2 \mathcal{M}_{\Gamma}-\mathcal{M}_{-S}-\mathcal{M}_{-T}-\mathcal{M}_{\Gamma}+\mathcal{M}_{-(S \cup T)} \\
=2\left(P_{\Gamma}\left(E_{\Gamma}\right)+\alpha W\left(E_{\Gamma}\right)\right)-P_{-S}\left(E_{-S}\right)-\alpha W\left(E_{-S}\right) \\
-P_{-T}\left(E_{-T}\right)-\alpha W\left(E_{-T}\right)-P_{\Gamma}\left(E_{\Gamma}\right)-\alpha W\left(E_{\Gamma}\right)+\alpha W\left(E_{*}\right) \\
\leq 2\left(P_{\Gamma}\left(E_{\Gamma}\right)+\alpha W\left(E_{\Gamma}\right)\right)-P_{-S}\left(E_{\Gamma}\right)-\alpha W\left(E_{\Gamma}\right) \\
-P_{-T}\left(E_{\Gamma}\right)-\alpha W\left(E_{\Gamma}\right)-P_{\Gamma}\left(E_{*}\right)-\alpha W\left(E_{*}\right)+\alpha W\left(E_{*}\right) \\
=2 P_{\Gamma}\left(E_{\Gamma}\right)-P_{-S}\left(E_{\Gamma}\right)-P_{-T}\left(E_{\Gamma}\right)-P_{\Gamma}\left(E_{*}\right) \\
=P_{\Gamma}\left(E_{\Gamma}\right)-P_{\Gamma}\left(E_{*}\right)
\end{gathered}
$$

where the inequality follows from the definition in (A.29) applied to $-S,-T$ and $\Gamma$, and the last equality from $P_{\Gamma}\left(E_{\Gamma}\right)=P_{-S}\left(E_{\Gamma}\right)+P_{-T}\left(E_{\Gamma}\right)$. The terms in (A.38) can be written as

$$
\begin{gathered}
P_{\Gamma}\left(E_{\Gamma}\right)-P_{\Gamma}\left(E_{*}\right)=P_{\Gamma}\left(E_{\Gamma}\right)+D_{0}\left(E_{*}\right)-P_{\Gamma}\left(E_{*}\right)-D_{0}\left(E_{*}\right) \\
=P_{\Gamma}\left(E_{\Gamma}\right)+D_{0}\left(E_{*}\right)-W\left(E_{*}\right) \\
<P_{\Gamma}\left(E_{\Gamma}\right)+D_{0}\left(E_{\Gamma}\right)-W\left(E_{*}\right)
\end{gathered}
$$

because $E_{\Gamma}>E_{*}$. The right-side equals $W\left(E_{\Gamma}\right)-W\left(E_{*}\right)$, which is strictly negative by (A.29). This means that the truthful equilibrium is unique. 


\section{Details of the example}

Stage 2: Proposition 1 states that the given aggregate quota $E$ is divided between the principals such that $c_{1}\left(\bar{e}_{1}-e_{1}\right)=c_{2}\left(\bar{e}_{2}-e_{2}\right)$ and $e_{1}+e_{2}=E$. These imply that

$$
e_{1}^{0}=\frac{c_{2} E+c_{1} \bar{e}_{1}-c_{2} \bar{e}_{2}}{c_{1}+c_{2}}, \quad e_{2}^{0}=\frac{c_{1} E+c_{2} \bar{e}_{2}-c_{1} \bar{e}_{1}}{c_{1}+c_{2}} .
$$

Equation (9) implies that the contributions evaluated at these quota levels are

$$
C_{1}^{0}\left(e_{1}^{0}\right)=\pi_{2}\left(e_{2}^{-1}\right)+\alpha\left(\pi_{1}\left(e_{1}^{-1}\right)+\pi_{2}\left(e_{2}^{-1}\right)\right)-\left(\pi_{2}\left(e_{2}^{0}\right)+\alpha\left(\pi_{1}\left(e_{1}^{0}\right)+\pi_{2}\left(e_{2}^{0}\right)\right)\right),
$$

and

$$
C_{2}^{0}\left(e_{2}^{0}\right)=\pi_{1}\left(e_{1}^{-2}\right)+\alpha\left(\pi_{1}\left(e_{1}^{-2}\right)+\pi_{2}\left(e_{2}^{-2}\right)\right)-\left(\pi_{1}\left(e_{1}^{0}\right)+\alpha\left(\pi_{1}\left(e_{1}^{0}\right)+\pi_{2}\left(e_{2}^{0}\right)\right)\right),
$$

where $\left(e_{1}^{-1}, e_{2}^{-1}\right)$ and $\left(e_{1}^{-2}, e_{2}^{-2}\right)$ are defined by Part (4) of Definition 1 as

$$
\left(e_{1}^{-1}, e_{2}^{-1}\right):=\arg \max _{\left(e_{1}, e_{2}\right) \in B}\left\{C_{2}^{0}\left(e_{2}\right)+\alpha\left(\pi_{1}\left(e_{1}\right)+\pi_{2}\left(e_{2}\right)\right)\right\},
$$

and

$$
\left(e_{1}^{-2}, e_{2}^{-2}\right):=\arg \max _{\left(e_{1}, e_{2}\right) \in B}\left\{C_{1}^{0}\left(e_{1}\right)+\alpha\left(\pi_{1}\left(e_{1}\right)+\pi_{2}\left(e_{2}\right)\right)\right\},
$$

with $B:=\left\{\left(e_{1}, e_{2}\right) \mid e_{1}+e_{2}=E\right\}$. A solution to the problem in (A.45) with strictly positive emission levels solves (using $C_{2}^{0 \prime}=\pi_{2}^{\prime}$ and $e_{1}+e_{2}=E$ )

$$
-c_{2}\left(\bar{e}_{2}-\left(E-e_{1}\right)\right)+\alpha\left(c_{1}\left(\bar{e}_{1}-e_{1}\right)-c_{2}\left(\bar{e}_{2}-\left(E-e_{1}\right)\right)\right)=0 .
$$

Using $\bar{e}_{2}=\bar{E}-\bar{e}_{1}$ and solving this for $e_{1}$ gives

$$
e_{1}^{-1}=\bar{e}_{1}-\frac{(1+\alpha) c_{2}}{(1+\alpha) c_{2}+\alpha c_{1}}(\bar{E}-E) .
$$

(Note that as $\alpha \rightarrow \infty, e_{1}^{-1} \rightarrow e_{1}^{0}$.) This and $e_{1}+e_{2}=E$ give

$$
e_{2}^{-1}=\frac{(1+\alpha) c_{2} \bar{E}+c_{1} E \alpha}{(1+\alpha) c_{2}+\alpha c_{1}}-\bar{e}_{1} \text {. }
$$

Similarly, (A.46) and $e_{1}+e_{2}=E$ imply

$$
\left(e_{1}^{-2}, e_{2}^{-2}\right)=\left(\frac{(1+\alpha) c_{1} \bar{E}+c_{2} E \alpha}{(1+\alpha) c_{1}+\alpha c_{2}}-\bar{e}_{2}, \bar{e}_{2}-\frac{(1+\alpha) c_{1}}{(1+\alpha) c_{1}+\alpha c_{2}}(\bar{E}-E)\right) .
$$

The equilibrium quotas at this stage are given by (A.42), and the equilibrium contributions are given by (A.43) and (A.44).

Stage 1: The equilibrium aggregate quota solves equation 


$$
\begin{gathered}
\left(1+\frac{1}{\alpha}\right)\left(c_{1}\left(\bar{e}_{1}-e_{1}^{0}\right) \frac{c_{2}}{c_{1}+c_{2}}+c_{2}\left(\bar{e}_{2}-e_{2}^{0}\right) \frac{c_{1}}{c_{1}+c_{2}}\right) \\
-d_{0}-\left(1+\frac{1}{\alpha}\right)\left(d_{1}+d_{2}\right)=0,
\end{gathered}
$$

and is given by

$$
E^{0}=\bar{E}-d_{0} \frac{\alpha}{1+\alpha} \frac{c_{1}+c_{2}}{c_{1} c_{2}}-\left(d_{1}+d_{2}\right) \frac{c_{1}+c_{2}}{c_{1} c_{2}} .
$$

The equilibrium contributions are calculated in a similar way as in Stage 2.

Equation (A.42) implies that the equilibrium individual quotas are

$$
e_{1}^{0}=\bar{e}_{1}-d_{0} \frac{\alpha}{1+\alpha} \frac{1}{c_{1}}-\frac{d_{1}+d_{2}}{c_{1}}
$$

and

$$
e_{2}^{0}=\bar{e}_{2}-d_{0} \frac{\alpha}{1+\alpha} \frac{1}{c_{2}}-\frac{d_{1}+d_{2}}{c_{2}} .
$$

Acknowledgements I wish to thank Carlo Carraro for early discussions and Markku Ollikainen, Jamie Jenkins and the participants of IIPF Annual Congress 2020 for comments. This paper has received funding from the European Union's Horizon 2020 research and innovation programme under the Marie Skłodowska-Curie Grant Agreement $\mathrm{N}^{\circ} 748066$.

Funding Open access funding provided by University of Helsinki including Helsinki University Central Hospital.

Open Access This article is licensed under a Creative Commons Attribution 4.0 International License, which permits use, sharing, adaptation, distribution and reproduction in any medium or format, as long as you give appropriate credit to the original author(s) and the source, provide a link to the Creative Commons licence, and indicate if changes were made. The images or other third party material in this article are included in the article's Creative Commons licence, unless indicated otherwise in a credit line to the material. If material is not included in the article's Creative Commons licence and your intended use is not permitted by statutory regulation or exceeds the permitted use, you will need to obtain permission directly from the copyright holder. To view a copy of this licence, visit http://creativecommons.org/licen ses/by/4.0/.

\section{References}

Aidt, T. (1998). Political internalization of economic externalities and environmental policy. Journal of Public Economics, 69, 1-16.

Barrett, S. (1994). Self-enforcing international environmental agreements. Oxford Economic Papers, 46, 878-894.

Bergemann, D., \& Välimäki, J. (2003). Dynamic common agency. Journal of Economic Theory, 111, 23-48.

Bernheim, D., \& Whinston, M. (1986). Menu auctions, resource allocation, and economic influence. The Quarterly Journal of Economics, 101, 1-32.

Bramoullé, Y., \& Orset, C. (2018). Manufacturing doubt. Journal of Environmental Economics and Management, 90, 119-133. 
Damania, R., Fredriksson, P., \& List, J. (2003). Trade liberalization, corruption, and environmental policy formation: Theory and evidence. Journal of Environmental Economics and Management, 46, 490-512.

Finkelshtain, I., \& Kislev, Y. (1997). Prices versus quantities: The political perspective. Journal of Political Economy, 105, 83-100.

Fredriksson, P. (1997). The political economy of pollution taxes in a small open economy. Journal of Environmental Economics and Management, 33, 44-58.

Fredriksson, P., \& Svensson, J. (2003). Political instability, corruption and policy formation: The case of environmental policy. Journal of Public Economics, 87, 1383-1405.

Grey, F. (2018). Corporate lobbying for environmental protection. Journal of Environmental Economics and Management, 90, 23-40.

Grossman, G., \& Helpman, E. (1994). Protection for sale. The American Economic Review, 84, 833-850.

Grossman, G., \& Helpman, E. (2001). Special interest politics (1st ed.). USA: The MIT Press.

Habla, W., \& Winkler, R. (2013). Political influence on non-cooperative international climate policy. Journal of Environmental Economics and Management, 66, 219-234.

Karp, L., \& Rezai, A. (2014). The political economy of environmental policy with overlapping generations. International Economic Review, 55, 711-733.

Lai, Y. (2007). The optimal distribution of pollution rights in the presence of political distortions. Environmental and Resource Economics, 36, 367-388.

Lai, Y. (2008). Auctions or grandfathering: The political economy of tradable emission permits. Public Choice, 136, 181-200.

Laussel, D., \& Le Breton, M. (2001). Conflict and cooperation: The structure of equilibrium payoffs in common agency. Journal of Economic Theory, 100, 93-128.

Marchiori, C., Dietz, S., \& Tavoni, A. (2017). Domestic politics and the formation of international environmental agreements. Journal of Environmental Economics and Management, 81, 115-131.

Persson, T., \& Tabellini, G. (1994). Does centralization increase the size of government. European Economic Review, 38, 765-773.

Yu, Z. (2005). Environmental protection: A theory of direct and indirect competition for political influence. The Review of Economic Studies, 72, 269-286.

Publisher's Note Springer Nature remains neutral with regard to jurisdictional claims in published maps and institutional affiliations. 